\title{
NOVITATES GABONENSES 74. A NEW SPECIES OF CARPOLOBIA (POLYGALACEAE) FROM GABON AND ADJACENT CONGO
}

\author{
F.J. BRETELER
}

The new species Carpolobia gabonica Breteler (Polygalaceae) from Gabon and adjacent Congo is described and illustrated. It is most closely related to Carpolobia gossweileri (Exell) E.M.A.Petit. The differences between the two species are summarised in a key which also includes Carpolobia alba G.Don, the only other species from that area.

Keywords. Carpolobia, Congo Brazzaville, Gabon, new species, Polygalaceae.

\section{INTRODUCTION}

The African genus Carpolobia G.Don (Polygalaceae) was revised by Breteler \& Smissaert-Houwing in 1977. It comprises four species of which Carpolobia alba G.Don, a forest shrub of up to c.5 m, and C. gossweileri (Exell) E.M.A.Petit, a small to medium-sized forest tree, occur in Gabon and adjacent Congo. The other two species are Carpolobia lutea G.Don from West Africa and Carpolobia goetzei Gürke from East Africa and Madagascar. The new species was first collected in SW Gabon in 1986, in an area, like many others in Gabon, that is botanically poorly explored. Recently it has been collected several times in flower in the same area and also in the Mayombe area of neighbouring Congo.

\section{SPecies Description}

Carpolobia gabonica Breteler, sp. nov. Figs 1, 2.

Carpolobia gossweileri (Exell) E.M.A.Petit maxime simile foliis magnis pistilliis fructibusque pilosis, sed ab ea differt habitu fruticoso, fructibus dense velutinis et seminibus adpresse-pilosis. - Type: Gabon, $46 \mathrm{~km}$ on track from Doussala to Igotchi, $2^{\circ} 40^{\prime} \mathrm{S}, 10^{\circ} 32^{\prime} \mathrm{E}, 29$ xi 1986, J.J. de Wilde, Arends \& de Bruijn 9043 (holo WAG; iso BR, LBV, MO, P).

Shrub-treelet, up to $3 \mathrm{~m}$ tall. Branchlets glabrous to puberulous-tomentellous, soon glabrescent or not. Pseudostipules (see note below and Fig. 1B) subulate, falcate or not, 2-3(-5) mm long, glabrous to puberulous-tomentellous; stipular glands often present. Leaves: petiole \pm terete, 2-3(-5) mm long, mostly canaliculate or grooved 


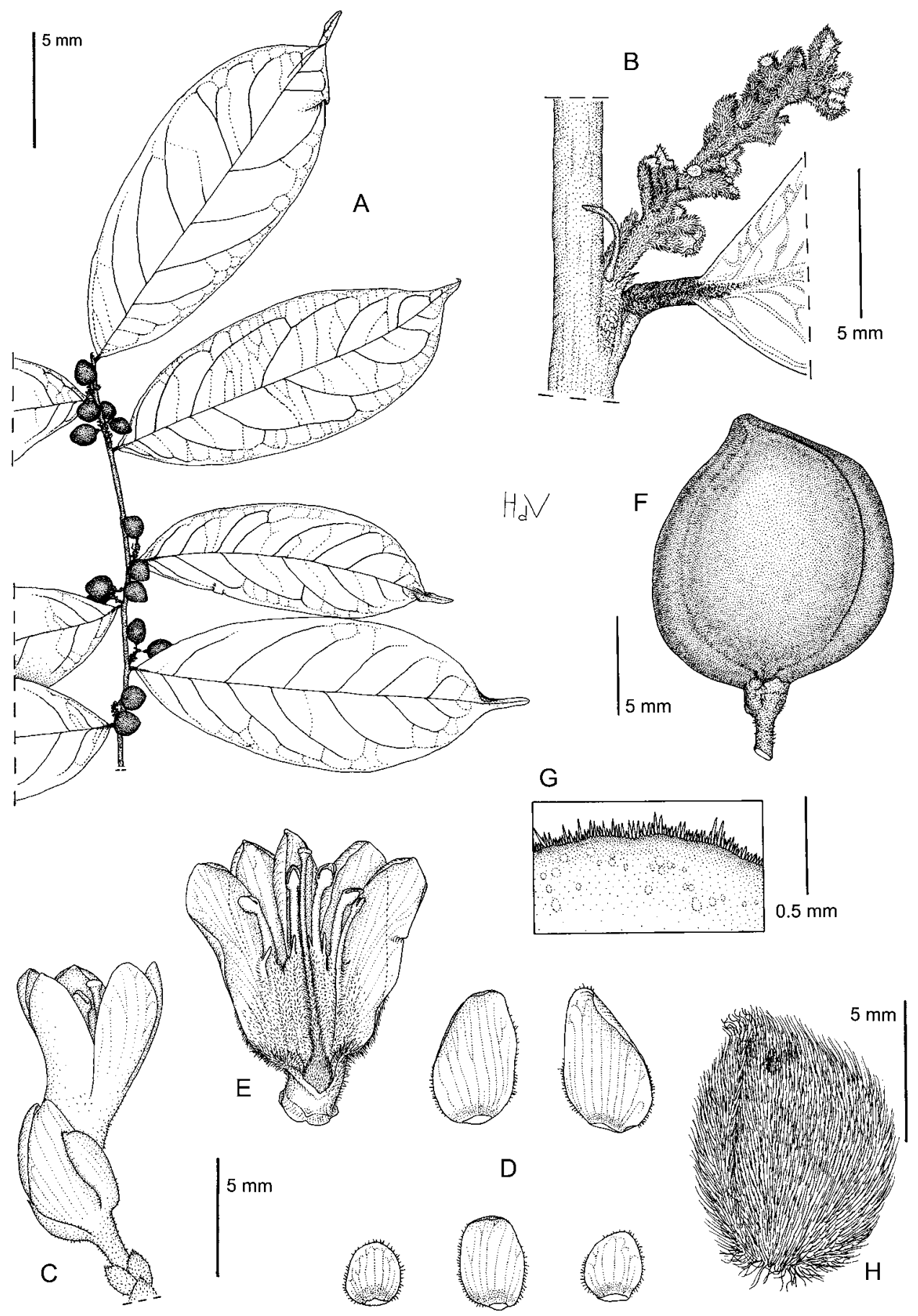

FIG. 1. Carpolobia gabonica Breteler. A, fruiting branch; B, leaf axil with pseudostipule and inflorescence axis; C, flower; D, sepals; E, opened up corolla with stamens and pistil; F, fruit; $\mathrm{G}$, detail of fruit indumentum; H, seed (A, B, F-H, J.J. de Wilde et al. 9043; C-E, Bissiengou et al. 351). Drawn by H. de Vries. 


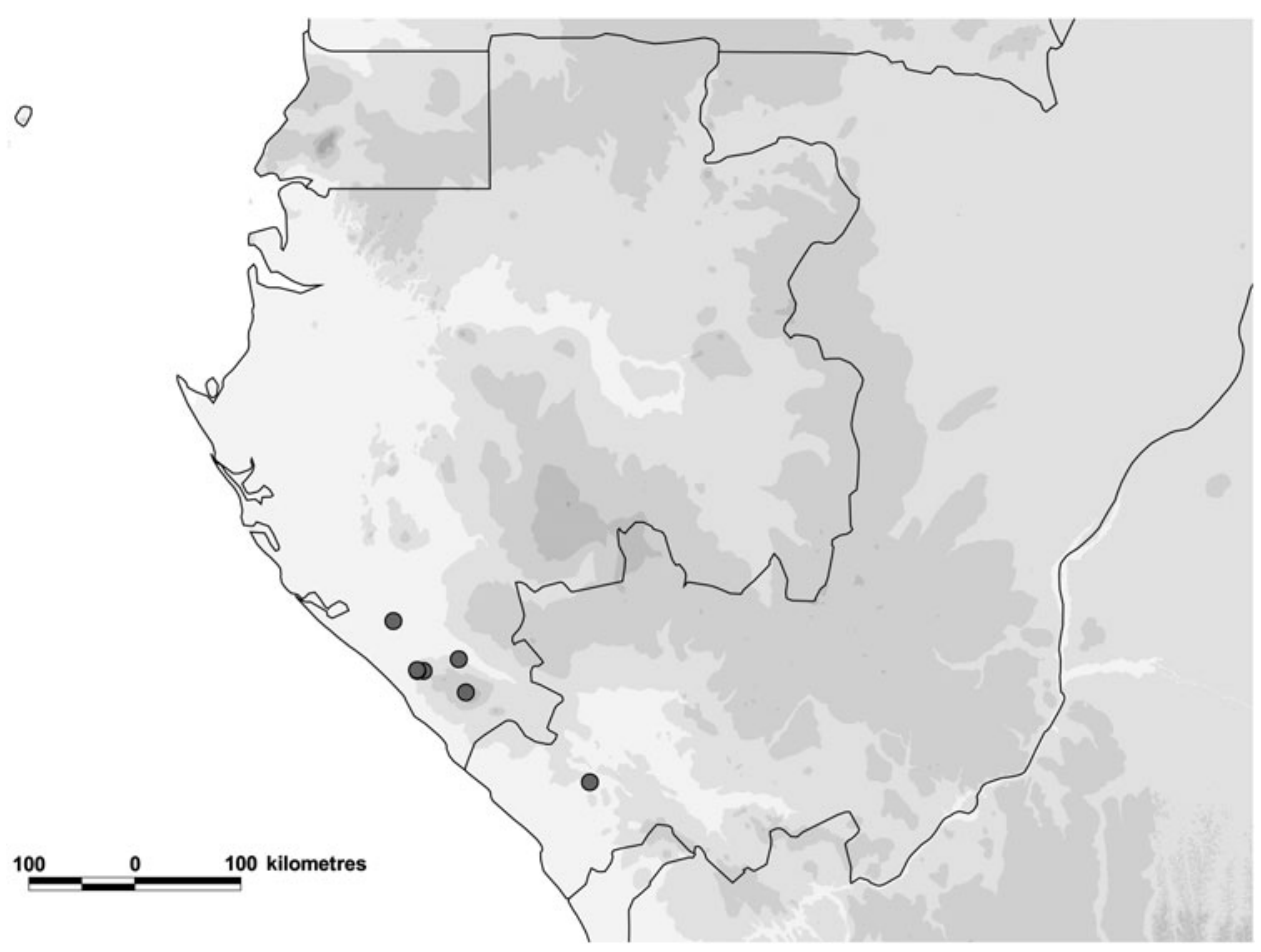

FIG. 2. Distribution of Carpolobia gabonica Breteler in Gabon and adjacent Congo.

above, glabrous, to sparsely puberulous-tomentellous; blade papery to thinly coriaceous, elliptic to obovate-oblong, 2.5-3 times as long as wide, $(11-) 14-18(-25) \times$ $(3.5-) 6-8.5 \mathrm{~cm}$, rounded to broadly cuneate at base, $(0.5-) 1-3 \mathrm{~cm}$ long acuminate at apex; midrib impressed above, prominent beneath; lateral nerves (7-)8-11(-15) on each side of the midrib, prominent both sides, reticulate tertiary nervation prominent on both sides; glabrous on both sides or puberulous-tomentellous on the impressed midrib and sometimes also sparingly so on the main laterals above, \pm sparsely puberulous-tomentellous throughout beneath. Inflorescence an axillary raceme, pubescent, up to c.10(-15)-flowered; axis up to c.10(-15) $\mathrm{mm}$ long; bracts and bracteoles \pm ovate, concave, 1-2 mm long. Flowers 11-12 mm long; pedicel 2$3 \mathrm{~mm}$ long, puberulous-tomentellous; sepals strongly unequal, circular to elliptic, 2.5-5 $\times 2.5-3 \mathrm{~mm}$, concave, sparsely appressed-puberulous outside, glabrous inside, margin ciliate; petals subequal in shape and length, narrowly obovate, $10-11 \mathrm{~mm}$ long, c. $5 \mathrm{~mm}$ adnate to the staminal sheath, this adnate part pubescent outside, the lobes glabrous or ciliate in the basal part and along the free edges; fertile stamens 5 , slightly shorter than the petals, at base united into a c. $5 \mathrm{~mm}$ long, hairy sheath, free part of filaments glabrous; staminodes 3-4, minute; pistil nearly as long as the petals, longer than the stamens, ovary and lower half of style puberulous; disc not developed. Pedicel in fruit 2-3 mm long, puberulous. Fruit nearly mature, shortly 
ovoid, slightly trigonous, $10-12 \mathrm{~mm}$ in diameter, slightly apiculate, densely shortly velutinous. Seed subellipsoid, densely appressed-hairy.

Distribution and habitat. Old secondary to primary evergreen rainforest in SW Gabon and adjacent Congo. Altitude up to c.300 m.

Additional specimens examined. GABon. Nyanga, Tchibanga-Mayumba Rd, 20 x 2009, Bissiengou, Boussiengui, Breteler \& Niangadouma 351 (E, LBV, WAG), 377 (LBV, WAG); ibid., 21 x 2009, Bissiengou, Boussiengui, Breteler \& Niangadouma 394 (E, LBV, WAG); NE of Tchibanga, 25 x 2009, Bissiengou, Boussiengui, Breteler \& Niangadouma 504 (LBV, WAG); Tchibanga Moulengui Binza Rd, 26 x 2009, Bissiengou, Boussiengui, Breteler \& Niangadouma 542 (LBV, WAG).

Congo (Brazzaville). Mayombe area, Manzi-Gomandgoma Rd, 11 x 2007, Becker 894 (WAG).

The three species of Carpolobia from Gabon and adjacent Congo may be distinguished as follows.

1a. Ovary and fruit glabrous; leaves $1.5-12.5(-15) \times 1-5(-6.5) \mathrm{cm}$ with $(3-) 4-7(-9)$ main laterals on each side of the midrib; shrub-treelet up to $5(-10$ ?) $\mathrm{m}$ tall C. alba

1b. Ovary and fruit hairy; leaves $(5-) 7-18(-25) \times(1.5-) 2.5-8.5 \mathrm{~cm}$ with (3-)5-11 $(-15)$ main laterals on each side of the midrib 2

2a. Tree up to $28 \mathrm{~m}$ tall; fruit puberulous-tomentellous, fruit surface visible between the hairs; seed erect-hairy C. gossweileri

2b. Shrub-treelet up to $3 \mathrm{~m}$ tall; fruit densely, shortly velutinous, the fruit surface not visible between the hairs; seed appressed-hairy C. gabonica

The derivation of the slender, \pm axillary bracts, called 'pseudostipules' in the species description (situated at the base of the inflorescence in Fig. 1B) is a mystery. Their position in the leaf axil at the base of the axillary bud would suggest they are a pair of basal bracts subtending this bud. However, on closer inspection it can be seen that these pseudostipules are not attached to this axillary bud, but are borne beside it. Moreover, their shape is quite different from the shape of the bracts that are produced on the axis of the inflorescence as illustrated in Fig. 1B.

\section{ACKNOWLEDGEMENTS}

I am grateful to my wife B. J. M. Breteler-Klein Breteler for preparing the electronic version of the manuscript, to $\mathrm{Mr} \mathrm{H}$. de Vries for the fine drawing, and to Dr R. H. M. J. Lemmens for translating the species diagnosis into Latin.

\section{REFERENCE}

Breteler, F. J. \& Smissaert-Houwing, A. A. S. (1977). Revision of Atroxima Stapf and Carpolobia G. Don (Polygalaceae). Meded. Landbouwhogeschool Wageningen 77-18: 1-45. 